\title{
Carbonate platform production during the Cretaceous
}

Alexandre POHL ${ }^{1,2,3}$, Yannick DONNADIEU ${ }^{1}$, Yves GODDERIS ${ }^{4}$, Cyprien

\section{LANTEAUME ${ }^{1,5,6}$, Alex HAIRABIAN ${ }^{7}$, Camille FRAU ${ }^{1}$, Julien MICHEL ${ }^{1,5}$, Marie}

\section{LAUGIE ${ }^{1}$, John J. G. REIJMER ${ }^{7}$, Christopher R. SCOTESE ${ }^{\boldsymbol{p}}$, Jean BORGOMANO ${ }^{1}$.}

${ }^{I}$ Aix Marseille Univ, CNRS, IRD, Coll France, INRA, CEREGE. Aix-en-Provence, France

${ }^{2}$ Department of Earth Sciences, University of California, Riverside, CA, USA

${ }^{3}$ Biogéosciences, UMR 6282, UBFC/CNRS, Université Bourgogne Franche-Comté, 6

boulevard Gabriel, F-21000 Dijon, France

${ }^{4} U M R 5563$ Géosciences Environnement Toulouse, Observatoire Midi-Pyrénées, CNRS,

Toulouse, France

${ }^{5}$ MODIS Pau, 4 Rue Jules Ferry, Pau, France

${ }^{6}$ Total CSTJF, Avenue Larribeau, 64000 Pau, France

${ }^{7}$ College of Petroleum Engineering \& Geosciences, King Fahd University of Petroleum \&

Minerals, Dhahran 31261, Saudi Arabia

${ }^{8}$ Department of Earth \& Planetary Sciences, Northwestern University, Evanston, IL, 60201, USA

\section{ABSTRACT}

Platform carbonates are among the most voluminous of Cretaceous deposits. The production of carbonate platforms fluctuated through time. Yet, the reasons for these fluctuations are not well understood and the underlying mechanisms remain largely unconstrained. Here we document the long-term trend in Cretaceous carbonate platform preservation based on a new data compilation and use a climate-carbon cycle model to explore the drivers of carbonate platform production during the Cretaceous. We show that neritic carbonate preservation rates followed a 
24 unimodal pattern during the Cretaceous reaching maximum values during the mid Cretaceous

25 (Albian, $110 \mathrm{Ma}$ ). Coupled climate-carbon cycle modeling reveals that this maximum in

26 carbonate deposition results from a unique combination of high volcanic degassing rates and

27 widespread shallow-marine environments that served as a substrate for neritic carbonate

28 deposition. Our experiments demonstrate that the unimodal pattern in neritic carbonate

29 accumulation agrees well with most of the volcanic degassing scenarios for the Cretaceous. Our

30 results suggest that the first-order temporal evolution of neritic carbonate production during the

31 Cretaceous reflects changes in continental configuration and volcanic degassing. Geodynamics,

32 by modulating accommodation space, and turnovers in the dominant biota probably played a role

33 as well, but it is not necessary to account for the latter processes to explain the first-order trend in

34 Cretaceous neritic carbonate accumulation in our simulations.

\section{INTRODUCTION}

In the recent years, our knowledge of the geological evolution of the surficial carbon cycle

37 has greatly improved. Among the main advances is the reconstruction of the Phanerozoic

38 atmospheric $\mathrm{CO}_{2}$ (Berner, 2006; Foster et al., 2017). The fluctuations of the carbon sink due to

39 continental weathering as well as the change in solid Earth degassing have been at least partly

40 constrained, using models (Goddéris et al., 2014; Brune et al., 2017) or proxies (such as isotopes)

41 (Veizer et al., 1999; Cao et al., 2017). One major component of the carbon cycle, however, the

42 sedimentary carbonate sink, has been poorly investigated at the global scale. Many data have

43 been published, regarding carbonate accumulation fluxes (Bosscher and Schlager, 1993;

44 Kiessling et al., 2000), but data compilations and extrapolation at the global scale are scarce.

45 Carbonate sediments are the receptacle of the atmospheric $\mathrm{CO}_{2}$ that has been removed

46 from the atmosphere by weathering, which can be subsequently recycled along subduction zones 
47 (Mason et al., 2017; Pall et al., 2018). Carbonate sediment deposition thus reflects many coupled

48 processes. Identifying those processes through geological times is an unparalleled way to check

49 whether we have understood the overall functioning of the carbon cycle or not.

50 Here we investigate the production by carbonate platforms during the Cretaceous, one of

51 the most prolific periods of carbonate platform development (Kiessling et al., 2003). We

52 reconstruct temporal variations in platform carbonate deposition based on a new data

53 compilation and subsequently explore the drivers of the temporal trends in Cretaceous carbonate

54 production using a coupled climate-carbon cycle model.

\section{METHODS}

\section{Database of shallow-water carbonate preservation rates}

57 We compiled, from published studies, an extensive database of Cretaceous shallow-water

58 marine carbonate preservation rates (see the GSA Data Repository for the full database). The

59 latter were calculated by dividing the estimated sediment thickness by the stratigraphic interval

60 duration. Calculated preservation rates necessarily underestimate actual carbonate production

61 rates. Indeed, neritic carbonate accumulation is limited by depositional accommodation space. In

62 addition, deposits may subsequently undergo dissolution, erosion and compaction, and produced

63 sediments may be exported toward the basin. As a result of all those mechanisms acting to

64 reduce the thickness of the carbonates preserved on the shelves, preservation rates calculated

65 based on the geological record are typically one to several orders of magnitude lower than

66 production rates measured on present-day carbonate-secreting ecosytems such as coral reefs

67 (Bosscher, 1992; Strasser and Samankassou, 2003; Schlager, 2010). Therefore compiled

68 preservation rates are considered significant underestimations of the actual accumulation rates.

69 Considering the multiple mechanisms acting to reduce the thickness of the shallow-water 
70 carbonates preserved on the shelves, maximum preservation rates are further considered to be the

71 most representative of the original carbonate accumulation flux in ancient times.

\section{The GEOCLIM climate-carbon cycle model}

73 We used the GEOCLIM climate-carbon cycle model (see the Data Repository) to simulate

74 carbonate accumulation fluxes during the Cretaceous. The GEOCLIM model (Donnadieu et al.,

75 2006a) asynchronously couples a carbon cycle box model with a general circulation model. It

76 represents a significant improvement over the zero-dimensional GEOCARB-like models (Berner,

77 2006), since continental weathering rates are resolved spatially, which takes into account the

78 continental configuration and sea level (Goddéris et al., 2014). The carbon cycle box model is the

79 COMBINE model upgraded following Donnadieu et al. (2006a). It includes a robust

80 representation of the marine sub-cycles of inorganic and organic carbon, oxygen, alkalinity and

81 phosphorus. It explicitly represents the spatial distribution of silicate, basalt and carbonate

82 weathering as a function of climate. The oceans are modeled by 9 "boxes". The accumulation of

83 neritic carbonates takes place exclusively in the box representing the low-to-mid latitude

84 epicontinental photic zone, following Eqn. 1:

$$
\boldsymbol{F}=\boldsymbol{k}_{\text {cr }} \times \boldsymbol{A}_{\text {platform }} \times\left(\boldsymbol{\Omega}_{\text {ara }}-\mathbf{1}\right)^{1.7}(1)
$$

where $\mathrm{F}$ is the neritic carbonate depositional flux $\left(\mathrm{mol} \mathrm{yr}^{-1}\right), \mathrm{A}_{\text {platform }}$ is the shelf area

87 available to shallow-water carbonate deposition, derived from the paleogeographic

88 reconstructions, $\boldsymbol{\Omega}_{\text {ara }}$ is the model aragonite solubility ratio and $\mathrm{k}_{\mathrm{cr}}$ a calibration constant. This

89 formulation of neritic carbonate accumulation rates has been successfully used in previous

90 studies to investigate the consequences of the demise of carbonate platforms during the Middle-

91 Late Jurassic Transition (ca. 160 Ma; Donnadieu et al., 2011) and the effects of the breakup of

92 Pangea on neritic carbonate accumulation (Late Permian to Late Cretaceous; Donnadieu et al., 
93 2006a). The climatic component of GEOCLIM is the FOAM ocean-atmosphere model version

941.5 (Jacob, 1997), a mixed-resolution general circulation model that has been routinely used to

95 study climate in deep time, including during the Cretaceous (Donnadieu et al., 2006b; Ladant and

96 Donnadieu, 2016).

97 Simulations were conducted using the Cretaceous paleogeographical reconstructions of

98 Scotese (2016) and Scotese and Wright (2018) with deep-ocean bathymetry after Müller et al.

99 (2008). Changing solar luminosity values were modeled after the stellar physics of Gough

100 (1981). Earth's orbit around the Sun was circular (null eccentricity) and the obliquity was set to

$10122^{\circ}$. This orbital configuration provides an equal, annual insolation for both hemispheres with

102 minimal seasonal contrast.

103 RESULTS

104 Temporal variations in Cretaceous shallow-water carbonate preservation rates

105 At first order, Fig. 1 shows a unimodal pattern in neritic carbonate preservation rates

106 during the Cretaceous with background values $<70 \mathrm{~m} \mathrm{Myr}^{-1}$ and an excursion to higher

107 preservation rates up to $175-200 \mathrm{~m} \mathrm{Myr}^{-1}$ during the mid Cretaceous between $125 \mathrm{Ma}$ (Aptian)

108 and $95 \mathrm{Ma}$ (Cenomanian). This mid-Cretaceous maximum is a robust feature. It was already

109 highlighted by the previous Phanerozoic compilation of Bosscher and Schlager (1993). It

110 parallels the mid-Cretaceous local maximum in reefal carbonate production identified by

111 Kiessling et al. (2000). It also corresponds with the development of massive successions of

112 sediments in the Mediterranean Tethys (>100 m thick; Skelton and Gili, 2011) and with the

113 maximum in carbonate accumulation identified in the North American, Russian and Siberian

114 platforms (Whitten, 1976).

\section{Coupled climate-carbon cycle simulations}


The drivers of secular change in platform carbonate production have been the subject of

117 investigation for decades (Schlager, 1981; Bosscher and Schlager, 1993; Kiessling et al., 2000;

118 Donnadieu et al., 2006a). From a carbon cycle perspective, global carbonate deposition is tightly

119 linked to changes in continental silicate and carbonate weathering. However, several factors

120 impact the distribution of carbonate deposition between the open ocean and shallow-marine

121 platforms. Debate thus continues as to whether fluctuations in neritic carbonate accumulation

122 rates reflect changing environmental conditions such as global climate, evolving geodynamics

123 (e.g., continental configuration and subsidence) or intrinsic changes such as turnovers in

124 dominant biota, since different carbonate factories are known to be associated with different

125 carbonate production rates (e.g., Lanteaume et al., 2018). Previous attempts to identify these

126 complex relationships over the course of the Phanerozoic failed to reach any definitive

127 conclusions (Bosscher and Schlager, 1993; Kiessling et al., 2000).

128 Baseline simulations with present-day volcanism

129 We used the GEOCLIM climate-carbon cycle model (Donnadieu et al., 2006a) to

130 investigate the driving mechanisms for the Cretaceous trend in neritic carbonate deposition with

131 a special focus on the maximum in carbonate accumulation centered at $110 \mathrm{Ma}$ (see Fig. 1).

132 Simulations were run every 10 Myrs between $150 \mathrm{Ma}$ (Late Jurassic) and $60 \mathrm{Ma}$ (Paleocene).

133 For each time slice and associated continental configuration, the GEOCLIM model computed the

$134 p \mathrm{CO}_{2}$ value by balancing volcanic degassing with silicate weathering. The GEOCLIM model

135 simulated the associated climatic state and ocean biogeochemistry. Though the neritic carbonate

136 deposition rate was focus of our investigation, the simulated $p \mathrm{CO}_{2}$ was used to evaluate the fit of

137 our simulations to the latest $p \mathrm{CO}_{2}$ reconstruction of Foster et al. (2017). The latter criterion was 
138 chosen to compare our simulations to proxy data due to the critical role that $p \mathrm{CO}_{2}$ plays on ocean

$139 \mathrm{pH}$ and thus carbonate geochemistry.

140 In our baseline runs, the rate of volcanic degassing was set to the present-day value $(6.8 \times$

$141 \quad 10^{12}$ moles of carbon per year; Donnadieu et al., 2006a) (Fig. 2A); only the paleogeography and

142 associated climate varied from one time slice to another. Simulated $p \mathrm{CO}_{2}$ was lower than

143 indicated by the proxy compilation for most of the Cretaceous (Fig. 2B). Yet, an interesting

144 pattern emerged: the bimodal trend observed in the $\mathrm{COO}_{2}$ compilation between $120 \mathrm{Ma}$ and 60

145 Ma (grey shading in Fig. 2B) was well reproduced in the baseline runs (black line in Fig. 2B).

146 This suggests that the temporal variations in $\mathrm{pCO}_{2}$ reconstructed by Foster et al. (2017) between

$147120 \mathrm{Ma}$ and $60 \mathrm{Ma}$ may be largely due to the paleogeographical evolution. The total neritic

148 carbonate depositional flux simulated in the baseline runs varied very little between $150 \mathrm{Ma}$ and

$14960 \mathrm{Ma}$, showing only a local optimum at $80 \mathrm{Ma}$ (Fig. 2C).

$150 \quad$ Numerical simulations using Cretaceous volcanic degassing scenarios

151 In a second step, we used Cretaceous plate models and data compilations to derive

152 volcanic $\mathrm{CO}_{2}$ degassing scenarios, which could help reconcile the simulations with proxy-based

$153 p \mathrm{CO}_{2}$ reconstructions. Such modeling attempt faces limitations associated with the large

154 uncertainties in the reconstruction of Cretaceous volcanic degassing. Indeed, numerous studies

155 have been published trying to reconstruct one of the components of the degassing rate but there

156 is no reconstruction of the total $\mathrm{CO}_{2}$ degassing by the solid Earth at the geological timescale. The

157 lack of an integrated curve leaves us with the necessity to rely on incomplete reconstructions.

158 Such bias concerns both the modeling and data communities. For instance, McKenzie et al.

159 (2016) argue for a dominant role of degassing on the climatic evolution, based on a correlation 
160 between the Phanerozoic climate and their curve for the degassing of arc volcanism, although arc 161 volcanism is only one component of the total degassing.

162 The rationale that we adopted thus consists in using available constraints to compute total 163 volcanic degassing rates, expressed as ratios compared to the present-day value. We did not try 164 to identify the individual contributions of the different components: subduction zones, rifts, mid165 ocean ridges and arc volcanism. Instead, we followed the approach adopted by Berner in his 166 various versions of the seminal GEOCARB(SULF) model (Berner and Kothavala, 2001; Berner, 1672004,2006 ), which consists in scaling volcanic degassing with proxies for geodynamic activity 168 (e.g., subduction length). Although this approach will undoubtedly benefit from advances in 169 geodynamic models in the near future, it has been shown to produce very good results in the 170 GEOCARB model (Berner, 2006; Van Der Meer et al., 2014). In detail, we derived volcanic 171 degassing rates (Fig. 2A) from the length of subduction zones calculated by Van Der Meer et al. 172 (2014) (hereafter VDM14), from the area of subducted lithosphere reconstructed over the last 173180 Myrs by Engebretson et al. (1992) (E92), from the slab flux estimated by East et al. (2020) 174 (EA20) and from the continental arc activity compiled by Cao et al. (2017) (CAO17). We also 175 used the $\mathrm{C} 1$ ' and $\mathrm{C1}$ '" scenarios of Brune et al. (2017), which consider variable contributions of 176 rifts, mid-ocean ridges, subduction zones and continental arcs.

177 Our model does not account for the degassing from large igneous provinces (LIPs). It has 178 been shown (Dessert et al., 2001) that LIP degassing increases the atmospheric partial pressure 179 of $\mathrm{CO}_{2}$ for durations that do not exceed a few million years after the end of the onset. LIPs also 180 impact the carbonate system through short-term acidification of the ocean, just prior to the 181 response of the weathering system (Paris et al., 2016). However, we here explore the response of 182 the carbon cycle to processes acting at a longer timescale, in the order of ten million years. 
We tested each of the volcanic degassing scenarios in the GEOCLIM model. The best fit

184 to proxy data was obtained using the subduction-based degassing scenario E92 (Fig. 2B). The

185 neritic carbonate production flux associated with this best-guess scenario displayed a maximum

186 centered on $110 \mathrm{Ma}$ (Fig. 2C) that agreed well with our compilation of Cretaceous preservation

187 rates (see Fig. 1).

188 Analyzing the drivers of the Mid-Cretaceous maximum in carbonate accumulation

189 Despite the disparities in the volcanic degassing scenarios (Fig. 2A), most simulations

190 showed that the highest rates of neritic carbonate production occurred during the mid Cretaceous

191 (between ca. 120 and $80 \mathrm{Ma}$ ). The mid-Cretaceous unimodal pattern, bounded by an increase in

192 neritic carbonate production in the Early Cretaceous (120-130 Ma) and a decrease in neritic

193 carbonate production in the early Late Cretaceous $(80 \mathrm{Ma})$, was a robust pattern that was shared

194 by different degassing scenarios.

195 Comparison of the simulations that considered evolving volcanic degassing rates with the 196 baseline runs (color vs. black lines in Fig. 2C) revealed that the lowest-to-mid Cretaceous

197 increase in neritic carbonate production (130-120 Ma), at least partially, relied on an increase in

198 volcanic degassing rates. In addition, a sensitivity test that used a constant area of the neritic

199 environments available for carbonate deposition (dashed magenta line in Fig. 2C) demonstrated

200 that the latter area played a key role in the increase in shallow-marine carbonate production.

201 Indeed, the area of the continental shelves significantly rose between $130 \mathrm{Ma}$ and $120 \mathrm{Ma}$ in our

202 reconstructions (Fig. 3). This increase resulted from the strong eustatic rise that took place at that

203 time (Müller et al., 2008). In the E92 scenario, the increasing area of shallow-marine

204 environments strengthened the pattern of carbonate accumulation already imposed by changing

205 volcanism (Fig. 2C), by favoring the accumulation of carbonate in neritic environments at the 
expense of the open ocean. In other degassing scenarios that did not have a well-defined

207 maximum at 120-110 Ma (i.e., C1', C1', VDM14, CAO17, EA20), the increasing area of the

208 shallow-marine environments, alone, drove the increase in neritic carbonate production between

209130 and $120 \mathrm{Ma}$ (Figs. 2A,C). Regarding the decrease in carbonate production after $80 \mathrm{Ma}$, two

210 main mechanisms were in play; most scenarios showed a drop in volcanic degassing (Fig. 2A)

211 and a major eustatic fall (Müller et al., 2008) reduced the area of the shallow-marine

212 environments available to neritic carbonate deposition (Fig. 3).

\section{DISCUSSION}

214 Comparison of our simulated trend of shallow-water carbonate production with the

215 updated compilation of preservation rates allowed us to propose a mechanistic explanation to

216 temporal variations in the deposition of Cretaceous shallow-water carbonates. It would be even

217 more interesting and straightforward to compare our simulated fluxes with the volumes (instead

218 of vertical aggradation rates) of shallow-water carbonates produced during the Cretaceous.

219 Unfortunately, such comparison is hampered by the lack of robust quantification of these

220 volumes. For instance, Dutkiewicz et al. (2019) calculated platform carbonate accumulation

221 fluxes by multiplying the extent of the carbonate platforms mapped by Kiessling et al. (2003) by

222 globally-uniform preservation rates derived from the compilation of Bosscher and Schlager

223 (1993). Figure 1C reveals that the temporal trends of carbonate production simulated in

224 GEOCLIM and the preserved volumes reconstructed by Dutkiewicz et al. (2019) largely differ.

225 The estimates of Dutkiewicz et al. (2019) provide significantly lower values. The low values at

226 least partly reflect the action of dissolution, erosion, compaction and the export of the carbonates

227 toward the basin, which all tend to reduce the thickness of the carbonates deposited on the

228 shelves. Preserved volumes necessarily represent an underestimation of the volumes of carbonate 
actually produced (see Methods). Regarding the temporal trend, the reconstruction of Dutkiewicz

230 et al. (2019) does not provide any robust quantification of the variation in the production of

231 platform carbonates. Indeed, the approach of Dutkiewicz et al. (2019) consists in multiplying the

232 surface of the carbonate platforms documented in the geological database by a constant (i.e., a

233 uniform rate of vertical aggradation). The authors derived two values for this constant rate from

234 the compilation of Bosscher and Schlager (1993), which provided the lower (using $30 \mathrm{~m} \mathrm{Myr}^{-1}$ )

235 and upper (using $80 \mathrm{~m} \mathrm{Myr}^{-1}$ ) boundaries for their reconstructed trend (Fig. 1C). Our updated

236 compilation of preservation rates (Fig. 1), however, reveals that preservation rates cover a very

237 large range of values, from $<10$ to $200 \mathrm{~m} \mathrm{Myr}^{-1}$. While it probably reflects the best estimate that

238 can be produced at the global scale based on the current knowledge, the approach employed by

239 Dutkiewicz et al. (2019) neglects the spatio-temporal variations in carbonate accumulation rates

240 and thus exclusively reflects the evolution of the area of the carbonate platforms (compare Fig.

241 1C and Fig. 3). Skelton (2003) conducted similar calculations for the Aptian and Cenomanian.

242 Only the platforms of the Tethyan region were considered in these calculations, while

243 Dutkiewicz et al. (2019) considered the area of the platforms at the global scale. The fact that

244 both studies led to virtually identical values (Fig. 1C), although they focused on significantly

245 different spatial scales, highlights once again the difficulty to estimate the depositional flux by

246 neritic carbonates in the deep time. We argue that, considering the current difficulty to estimate

247 volumes of neritic carbonates produced in ancient times, our reconstructed neritic carbonate

248 preservation rates (Fig. 1) constitute an instructive proxy for the efficiency of the shallow-water

249 carbonate factory in ancient times. The reported temporal patterns are supported by both

250 previous data compilations (Whitten, 1976; Bosscher and Schlager, 1993; Kiessling et al., 2000)

251 and accumulation patterns observed in the field (Skelton and Gili, 2011). 
The simulated maximum in mid-Cretaceous neritic carbonate production results from the

254 combination of high volcanic degassing levels and the large shallow-marine realms. Although

255 the precise evolution of carbonate accumulation rates varies from one volcanic degassing

256 scenario to another, the unimodal pattern in neritic carbonate production simulated during the

257 Cretaceous is robust and shows up in most of the scenarios. The model results align well with the

258 temporal trend that emerges from the updated compilation of Cretaceous platform carbonate

259 preservation rates. Our results therefore suggest that the first-order evolution of neritic carbonate

260 deposition during the Cretaceous reflects changes in continental configuration and volcanic

261 degassing. Other mechanisms modulating accommodation space and turnovers in the dominant

262 biota probably played a role as well, but our simulations suggest that the latter processes do not

263 explain the first-order trend in Cretaceous neritic carbonate accumulation.

264 ACKNOWLEDGMENTS

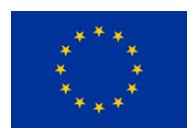

The authors thank Dietmar Müller, Peter Skelton and two anonymous reviewers for their

267 thorough reviews that significantly strengthened the present manuscript, and Judith Totman

268 Parrish and Gerald Dickens for editorial handling. A.P. and Y.D. thank the CEA/CCRT for

269 providing access to the HPC resources of TGCC under the allocation 2014-012212 made by

270 GENCI. The research leading to these results was supported by a Marie Sklodowska-Curie

271 International Fellowship under Grand Agreement no. 838373. The authors thank B. Suchéras-

272 Marx (CEREGE) for interesting discussions on the calcifying plankton during the Cretaceous, P.

273 Maffre (GET) for his assistance in setting-up our Cretaceous configuration of the GEOCLIM

274 model and S. Brune for providing degassing scenarios. 
REFERENCES CITED

277 Berner, R.A., 2006, GEOCARBSULF: A combined model for Phanerozoic atmospheric O2 and

278 CO2: Geochimica et Cosmochimica Acta, v. 70, p. 5653-5664,

279 http://www.sciencedirect.com/science/article/pii/S0016703706002031.

280 Berner, R.A., 2004, The phanerozoic carbon cycle CO2 s and O2: New York, Oxford University 281 Press.

282 Berner, R.A., and Kothavala, Z., 2001, GEOCARB III: a revised model of atmospheric CO2 283 over Phanerozoic time: American Journal of Science, v. 301, p. 182-204, $284 \mathrm{http} / /$ ajsonline.org/content/301/2/182.short.

285 Bosscher, H., 1992, Growth potential of coral reefs and carbonate platforms: 157 p. p.

286 Bosscher, H., and Schlager, W., 1993, Accumulation rates of carbonate platforms: Journal of 287 Geology, v. 101, p. 345-355, doi:10.1086/648228.

288 Brune, S., Williams, S.E., and Müller, R.D., 2017, Potential links between continental rifting, 289 CO2 degassing and climate change through time: Nature Geoscience, v. 10, p. 941-946, 290 doi:10.1038/s41561-017-0003-6.

291 Cao, W., Lee, C.-T.A., and Lackey, J.S., 2017, Episodic nature of continental arc activity since 292750 Ma: A global compilation: Earth and Planetary Science Letters, v. 461, p. 85-95.

293 Dessert, C., Dupré, B., François, L.M., Schott, J., Gaillardet, J., Chakrapani, G., and Bajpai, S., 294 2001, Erosion of Deccan Traps determined by river geochemistry: impact on the global 295 climate and the $87 \mathrm{Sr} / 86 \mathrm{Sr}$ ratio of seawater: Earth and Planetary Science Letters, v. 188, p. $296 \quad 459-474$.

297 Donnadieu, Y., Dromart, G., Goddéris, Y., Pucéat, E., Brigaud, B., Dera, G., Dumas, C., and 
Olivier, N., 2011, A mechanism for brief glacial episodes in the Mesozoic greenhouse: Paleoceanography, v. 26, p. PA3212, http://doi.wiley.com/10.1029/2010PA002100.

Donnadieu, Y., Goddéris, Y., Pierrehumbert, R., Dromart, G., Fluteau, F., and Jacob, R., 2006a, A GEOCLIM simulation of climatic and biogeochemical consequences of Pangea breakup: Geochemistry, Geophysics, Geosystems, v. 7, p. Q11019, http://doi.wiley.com/10.1029/2006GC001278.

Donnadieu, Y., Pierrehumbert, R., Jacob, R., and Fluteau, F., 2006b, Modelling the primary

Dutkiewicz, A., Müller, M.D., Cannon, J., Vaughan, S., and Zahirovic, S., 2019, Sequestration control of paleogeography on Cretaceous climate: Earth and Planetary Science Letters, v. 248, p. $426-437$.

Engebretson, D.C., Kelley, K.P., Cashman, H.J., and Richards, M.A., 1992, 180 Million Years of and subduction of deep-sea carbonate in the global ocean since the Early Cretaceous: Geology, v. 47, p. 91-94, doi:10.1130/G45424.1.

East, M., Müller, R.D., Williams, S., Zahirovic, S., and Heine, C., 2020, Subduction history reveals Cretaceous slab superflux as a possible cause for the mid-Cretaceous plume pulse

316 Foster, G.L., Royer, D.L., and Lunt, D.J., 2017, Future climate forcing potentially without precedent in the last 420 million years: Nature Communications, v. 8, p. 14845,

319 Goddéris, Y., Donnadieu, Y., Le Hir, G., Lefebvre, V., and Nardin, E., 2014, The role of 320 palaeogeography in the Phanerozoic history of atmospheric CO2 and climate: Earth-Science 
Reviews, v. 128, p. 122-138, doi:10.1016/j.earscirev.2013.11.004.

322 Gough, D.O., 1981, Solar interior structure and luminosity variations*: Solar Physics, v. 74, p. $323 \quad 21-34$.

324 Gradstein, F.M., Ogg, J.G., Schmitz, M., and Ogg, G. (Eds.), 2012, The Geologic Time Scale, $325 \quad$ Volumes $1 \& 2$ : Elsevier.

326 Jacob, R.L., 1997, Low frequency variability in a simulated atmosphere-ocean system:

327 University of Wisconsin Madison, $170 \mathrm{p}$.

328 Kiessling, W., Flügel, E., and Golonka, J., 2000, Fluctuations in the carbonate production of 329 Phanerozoic reefs: Geological Society Special Publication, v. 178, p. 191-215, 330 doi:10.1144/GSL.SP.2000.178.01.13.

331 Kiessling, W., Flügel, E., and Golonka, J., 2003, Patterns of phanerozoic carbonate platform 332 sedimentation: v. 36, 195-226 p., doi:10.1080/00241160310004648.

333 Ladant, J.-B., and Donnadieu, Y., 2016, Palaeogeographic regulation of glacial events during the 334 Cretaceous supergreenhouse: Nature communications, v. 7, p. 12771, 335 http://dx.doi.org/10.1038/ncomms12771.

336 Lanteaume, C., Fournier, F., Pellerin, M., and Borgomano, J., 2018, Testing geologic

337 assumptions and scenarios in carbonate exploration: Insights from integrated stratigraphic, 338 diagenetic, and seismic forward modeling: Leading Edge, v. 37, p. 672-680, 339 doi:10.1190/tle37090672.1.

340 Mason, E., Edmonds, M., and Turchyn, A. V, 2017, Remobilization of crustal carbon may 341 dominate dominate volcanic arc emissions: Science, v. 294, p. 290-294.

342 McKenzie, N.R., Horton, B.K., Loomis, S.E., Stockli, D.F., Planavsky, N.J., and Lee, C.-T.A., 3432016 , Continental arc volcanism as the principal driver of icehouse-greenhouse variability: 
Science, v. 352, p. 444-447.

345 Van Der Meer, D.G., Zeebe, R.E., Van Hinsbergen, D.J.J., Sluijs, A., Spakman, W., and Torsvik,

346 T.H., 2014, Plate tectonic controls on atmospheric CO2 levels since the Triassic:

347 Proceedings of the National Academy of Sciences of the United States of America, v. 111, p. 4380-4385, doi:10.1073/pnas.1315657111.

Müller, R.D., Sdrolias, M., Gaina, C., Steinberger, B., and Heine, C., 2008, Long-term sea-level

Pall, J., Zahirovic, S., Doss, S., Hassan, R., Matthews, K.J., Cannon, J., Gurnis, M., Moresi, L., fluctuations driven by ocean basin dynamics: Science, v. 319, p. 1357-1362, http://www.sciencemag.org/cgi/doi/10.1126/science.1151540. Lenardic, A., and Dietmar Müller, R., 2018, The influence of carbonate platform interactions with subduction zone volcanism on palaeo-atmospheric $\mathrm{CO} 2$ since the Devonian: Climate of the Past, v. 14, p. 857-870, doi:10.5194/cp-14-857-2018.

Paris, G., Donnadieu, Y., Beaumont, V., Fluteau, F., and Goddéris, Y., 2016, Geochemical consequences of intense pulse-like degassing during the onset of the Central Atlantic Magmatic Province: Palaeogeography, palaeoclimatology, palaeoecology, v. 441, p. 74-82, http://dx.doi.org/10.1016/j.palaeo.2015.04.011.

Schlager, W., 2010, Ordered hierarchy versus scale invariance in sequence stratigraphy: International Journal of Earth Sciences, v. 99, p. 139-151, doi:10.1007/s00531-009-0491-8.

Schlager, W., 1981, The paradox of drowned reefs and carbonate platforms: Geological Society

364 Scotese, C.R., 2016, PALEOMAP PaleoAtlas for GPlates and the PaleoData Plotter Program (PALEOMAP Project, 2016):, https://www.earthbyte.org/paleomap-paleoatlas-for-gplates/.

366 Scotese, C.R., and Wright, N., 2018, PALEOMAP Paleodigital Elevation Models (PaleoDEMS) 
for the Phanerozoic (PALEOMAP Project, 2018):, https://www.earthbyte.org/paleodemresource- scotese-and-wright-2018/.

369 Skelton, P.W., 2003, The operation of the major geological carbon sinks, in Skelton, P.W., 370 Spicer, R.A., Kelley, S.P., and Gilmour, I. eds., The Cretaceous World, Cambridge $371 \quad$ University Press, p. 259-266.

372 Skelton, P.W., and Gili, E., 2011, Rudists and carbonate platforms in the Aptian: a case study on 373 biotic interactions with ocean chemistry and climate: Sedimentology, v. 59, p. 81-117, 374 http://doi.wiley.com/10.1111/j.1365-3091.2011.01292.x.

375 Strasser, A., and Samankassou, E., 2003, Carbonate sedimentation rates today and in the past: 376 Holocene of Florida Bay, Bahamas, and Bermuda vs. Upper Jurassic and lower cretaceous 377 of the Jura mountains (Switzerland and France): Geologia Croatica, v. 56, p. 1-18, 378 doi:10.4154/GC.2003.01.

379 Veizer, J. et al., $1999,87 \mathrm{Sr} / 86 \mathrm{Sr}, \delta 13 \mathrm{C}$ and $\delta 18 \mathrm{O}$ evolution of Phanerozoic seawater: Chemical 380 Geology, v. 161, p. 59-88, doi:10.1016/S0009-2541(99)00081-9.

381 Whitten, E.H.T., 1976, Cretaceous phases of rapid sediment accumulation, continental shelf, 382 eastern USA: Geology, v. 4, p. 237-240, doi:10.1130/00917613(1976)4<237:CPORSA $>2.0 . C O ; 2$. 


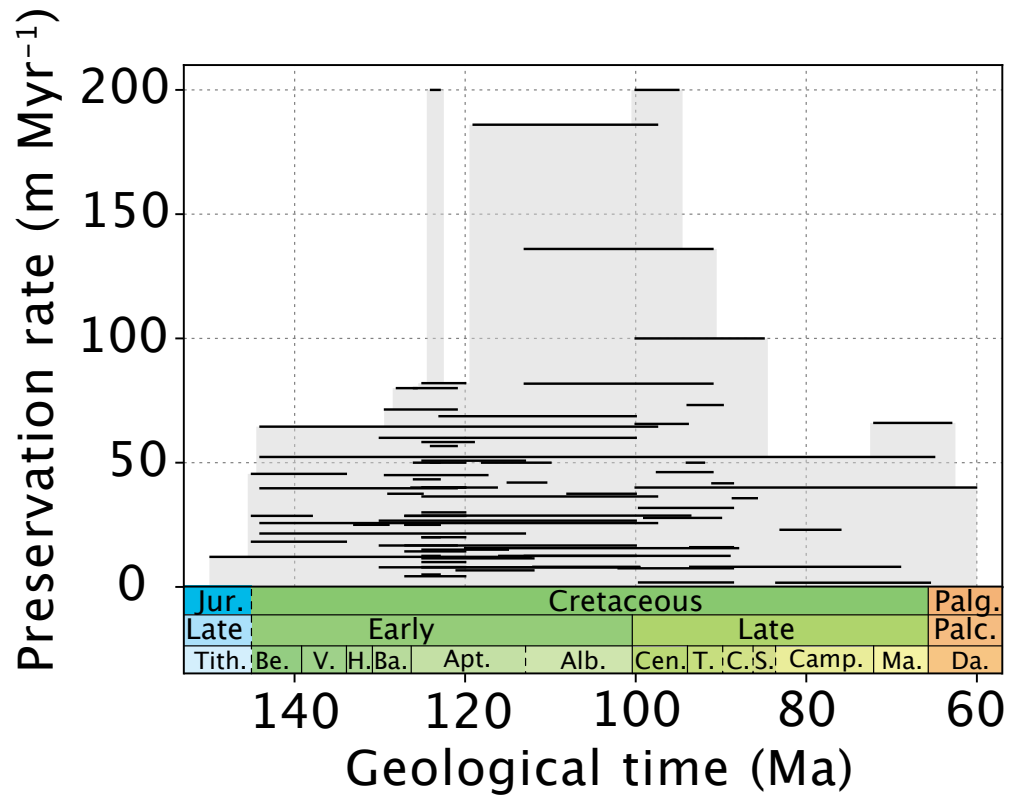

387 Figure 1. Compilation of Cretaceous neritic carbonate preservation rates. The light grey 388 envelope represents the maximum accumulation rates, which are likely to best represent neritic 389 carbonate production in ancient times (see Methods). Stratigraphic boundaries after Gradstein et 390 al. (2012). 

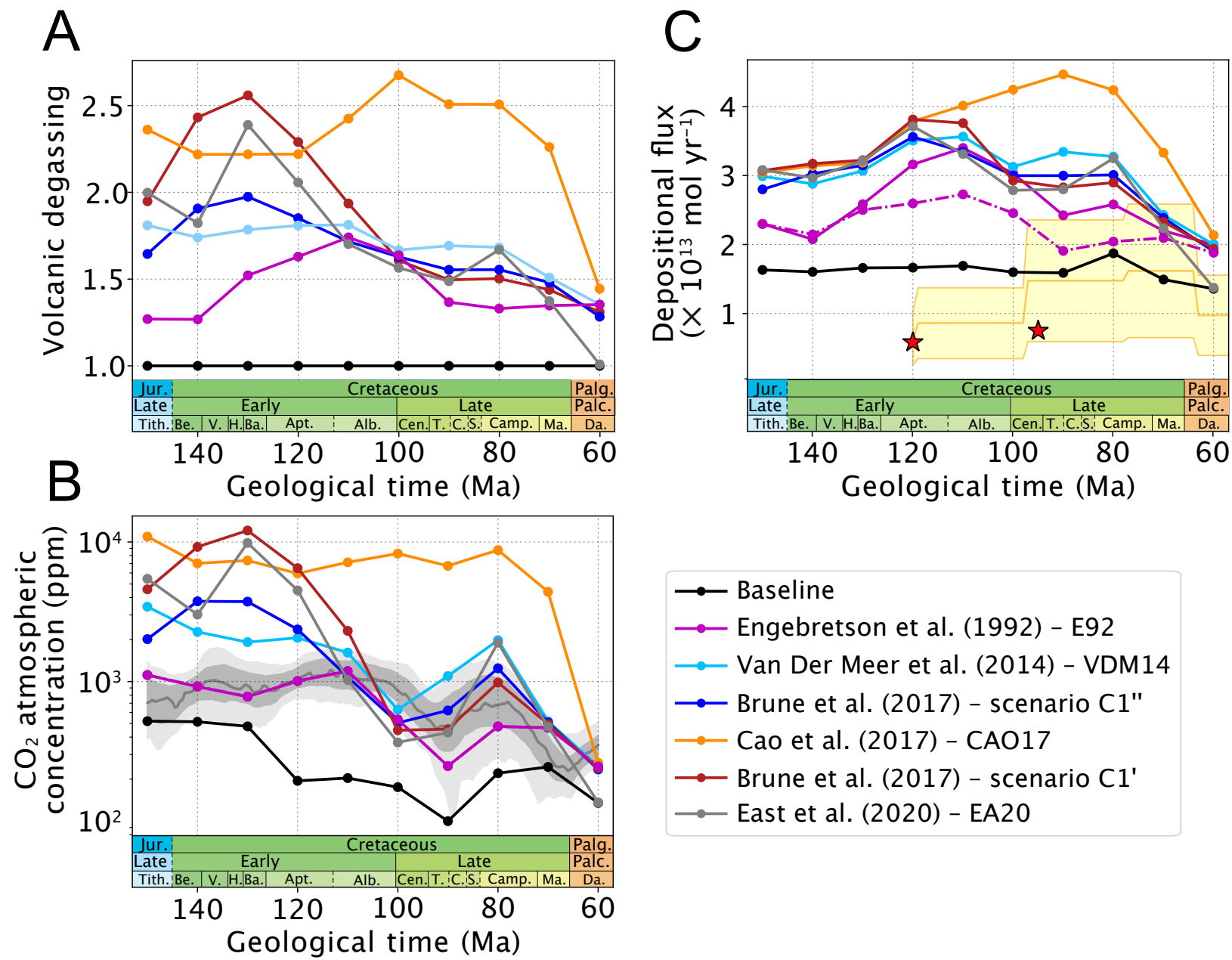

Figure 2. Model results. (A) Volcanic degassing scenarios used in the GEOCLIM model

393 (ratio to present-day value), (B) predicted atmospheric $\mathrm{CO}_{2}$ concentration and (C) predicted

394 neritic carbonate total depositional flux. Black line represents the baseline runs with volcanic

395 degassing set to the present-day level. Solid color lines represent volcanic degassing scenarios.

396 For scenario E92, the simulation represented with the dashed line is identical to the one

397 represented with the solid line except that it uses a constant area of the shallow-marine

398 environments available to neritic carbonate deposition during the Cretaceous. In panel B,

399 background grey shading represents the proxy-based $p \mathrm{CO}_{2}$ reconstruction of Foster et al. (2017)

400 with LOESS fit, $68 \%$ and $95 \%$ confidence intervals. In panel C, yellow shading and red stars 
401 respectively represent the platform carbonate accumulation fluxes estimated by Dutkiewicz et al.

402 (2019) and Skelton (2003) (see main text).

403

404

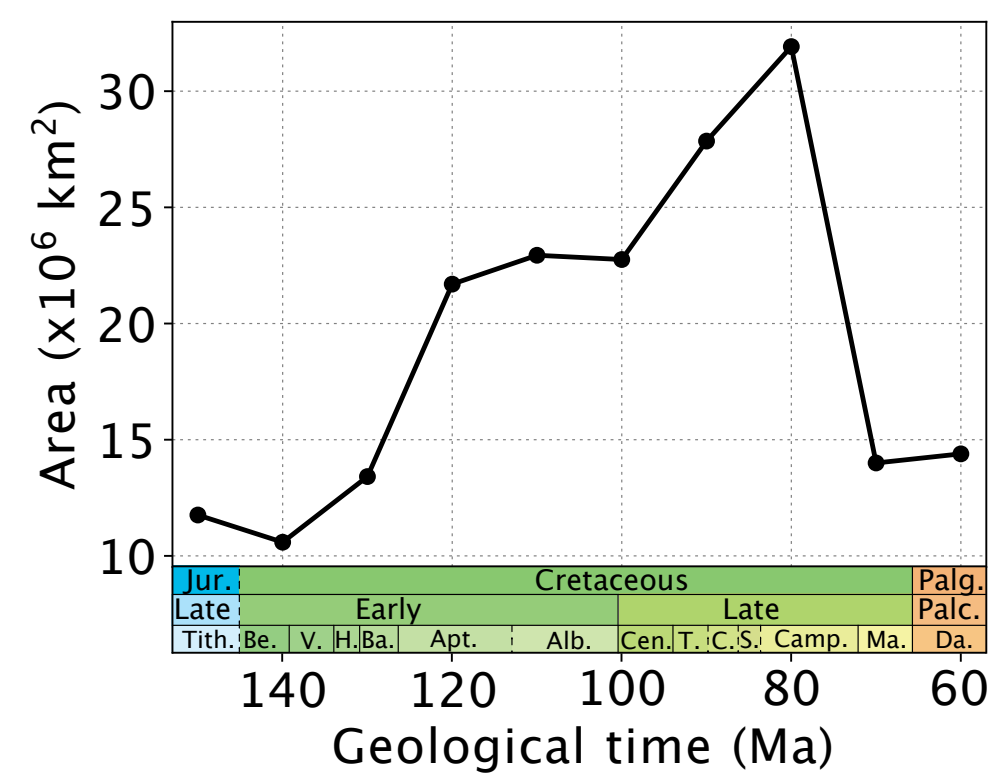

406 Figure 3. Area of the shallow-marine environments available to neritic carbonate

407 deposition, derived from the paleogeographical reconstructions (see the Data Repository).

408

$409{ }^{1}$ GSA Data Repository item 201Xxxx, [Supplementary information, geological database,

410 experimental setup and climate model runs (Sections DR1-DR2, Figures DR1-DR2, and Tables

411 DR1-DR2)], is available online at www.geosociety.org/pubs/ft20XX.htm, or on request from

412 editing@geosociety.org. 